\title{
Corrosion Protection of Aluminum Alloy by Sol-Gel Derived Organic-Inorganic Hybrid Pretreatments Based on Epoxy Resin Modified Silane Precursor
}

\author{
Mahshid Niknahad, Chintankumar J. Patel and Vijay Mannari \\ Coating Research Institute, Eastern Michigan University, Ypsilanti, MI, USA
}

\begin{abstract}
Organic-Inorganic hybrid $(\mathrm{OIH})$ derived by sol-gel process have emerged as promising pretreatments alternative to conventional chromate-based systems for aluminum alloys.

In this study novel organo-silane precursor has been synthesized from epoxy resin and amino-silane compound and used as the primary component of OIH film. The effects of epoxy and silane functionality and organic inhibitor used in the composition have been studied on corrosion resistance performance of aluminum alloy (3003-H14). The study also investigates the performance of top coat (powder coating) adhesion onto the pretreatment under different cure conditions. The chemical structure of sol-gel precursor (epoxy silane) and the deposited films have been characterized by FTIR analysis. The corrosion protection performance has been studied by electrochemical impedance spectroscopy (EIS), D.C. electrochemical polarization measurements, and the accelerated neutral salt spray test (ASTM B117). This study shows that by proper choice of precursor structure, functionality, processing conditions, and corrosion inhibitor amount, it is possible to derive $\mathrm{OlH}$ films with corrosion resistance performance comparable to conventional $\mathrm{Cr}(\mathrm{VI})$ based pretreatments.
\end{abstract}

Received on 01-03-2016 Accepted on 07-03-2016 Published on 24-05-2016

Keywords: Sol-gel, organicinorganic hybrid, epoxy silane, corrosion inhibitor, aluminum alloy.

\section{HIGH LIGHTS}

- Uniform, defect-free, "green" organic-inorganic hybrid pretreatments have been developed.

- $\quad$ GPTMS content and functionality of epoxy resin are the key factors affecting stability time of sol-gel bath and interaction with powder coating.

- $\quad$ Corrosion resistance property of $\mathrm{OlH}$ show synergist enhancement by organic inhibitor.

- $\quad$ Corrosion protection of aluminum substrate has been enhanced by formation of an efficient barrier to water and corrosive agents.

- $\quad$ Single-cure cycle for curing of both pretreatment and powder coating is not adequate.

- Corrosion resistance is comparable to conventional toxic $\mathrm{Cr}(\mathrm{VI})$ based pretreatment.

"Coatings Research Institute, Eastern Michigan University, Ypsilanti, MI 48197, USA; Tel: + 1(734)4871235; Fax: +1(734) 4878755;

E-mail:vmannari@emich.edu

\section{INTRODUCTION}

Aluminum alloys are increasingly used as materials of choice for many industrial, automotive and aerospace applications because of their light weight and high strength combined with many desirable mechanical properties. However, many aluminum alloys are sensitive to serious corrosion problems when exposed to corrosive environment [1,2]. The sensitivity of aluminum alloys for corrosion is also dependent on the alloy composition. Therefore, it is common practice in industry to use a multi-layer protective coating system for corrosion protection. Typically these multi-layer protective coating systems include a conversion pretreatment that is applied directly on the bare metal surface followed by a primer, and a top coat. The most common and effective pretreatments used in such protective systems is chromatebased conversion coatings (pretreatments) (CCC) [3, 4]. The CCC provides corrosion resistance and good foundation for adhesion of subsequent organic coatings, such as primer. Thus, the role of pretreatment is very critical to the success of the entire protective coating system.

Typically CCC consists of a salt of hexavalent chromium compound along with other ingredients. The formation of CCC is usually described as a redox reaction between 
oxidizing $\mathrm{Cr}(\mathrm{VI})$ ions and the substrate metal [5]. Chromate oxidizing ions $\left(\mathrm{CrO}_{4}{ }^{2-}\right.$ or $\left.\mathrm{Cr}_{2} \mathrm{O}_{7}{ }^{2-}\right)$ which are very soluble and higher-valent transform to a lower-valent form that is insoluble and create an extremely dense and protective film $\left[\mathrm{Cr}_{2} \mathrm{O}_{3}\right.$ or $\left.\mathrm{Cr}(\mathrm{OH})_{3}\right][6]$. The presence of small amount of free $\mathrm{Cr}(\mathrm{VI})$ ions in the CCC film are responsible for "self-healing" in the event when CCC film gets cracked or ruptured; $\mathrm{Cr}(\mathrm{VI})$ ions are believed to migrate to the exposed metal site and reproduce coating.

While chromate-based pretreatments provide outstanding corrosion inhibition, they are toxic and $\mathrm{Cr}(\mathrm{VI})$ is a known carcinogen [7]. Besides, the Occupational Safety and Health Administration (OSHA) studies have found that the application of the hexavalent chromium presents significant medical risks to users. The environmental and human health impacts as well as the costs associated with such systems have forced manufacturers to search for alternative nonchromate systems [8-13]. Among the several chrome-free conversion coatings developed for aluminum alloys, OIH films derived by sol-gel process have been found very promising. These systems have emerged as efficient, environmentallyfriendly and sustainable alternative to toxic heavy metalbased systems [14-18]. Hybrid materials containing both inorganic and organic components are expected to have good capabilities because of the compatibility between topcoat and substrate, caused by the existence of covalent bonding or strong interactions at the interface [17].

$\mathrm{OlH}$ films provide good adhesion between metals and organic primers by formation of functionalized films between metals and organic primers that improves interaction between sol-gel network and primers $[19,20]$. The chemistry of silanes and their mechanism of interaction with metallic substrates and organic coatings show that silanes, besides providing the adhesion between metal substrates and organic coatings, also provide a thin barrier film against oxygen diffusion to the metal interface [20].

In the present study, epoxy resin derived bis-silane compounds have been chosen as primary sol-gel precursors. Bis-silanes, by virtue of their six reactive functional sites, form up to six silanol groups and hence increase the probability of reactions of these silanol groups with $-\mathrm{OH}$ groups on the metallic surface [21]. Bis-silanes tend to bond to metal substrates more tightly than the mono-silanes. The former with more alkoxide groups is able to develop a much denser interfacial region through hydrolysis and condensation reactions [22]. It was always observed in corrosion performance tests that bis-silanes offered a much improved corrosion protection than the mono-silanes on various metals and alloys, such as Al and Al alloys, steels, $\mathrm{Zn}$ and $\mathrm{Zn}$-coated steels, $\mathrm{Cu}$ and $\mathrm{Cu}$ alloys, and $\mathrm{Mg}$ and $\mathrm{Mg}$ alloys [23, 24]. Epoxy resins are very versatile and are widely used in many practical applications. Very often their properties can be effectively modified by an addition of reactive silanes [25]. In addition epoxy-silica hybrids show enhanced functional properties compared to the neat epoxy networks [26, 27].
Compared to the traditional chromate conversion treatments the only major limitation of silane-based $\mathrm{OlH}$ is that, in general, they do not provide an active protection to the metallic substrate. In fact, when water and aggressive ions reach the surface of the metal, OIH layers are not able to ensure an active inhibition of the corrosion process as well as chromates compounds [28]. To improve the protection properties of the silane-based OlH layers, several attempts have been made by adding organic or inorganic inhibitors to $\mathrm{OIH}$ films $[29,30]$. The addition of corrosion inhibitors to pretreatments can enhance the interface stability by delaying corrosion induced delamination at the damage sites [29, 31]. Many types of inhibitors have been used to increase the corrosion protective properties of $\mathrm{OlH}$ films. Effectiveness of inhibitors in the silane film depends on a number of factors such as the solubility of the inhibitors, leachability of the inhibitors, the permeability of the silane coating, and the compatibility of the inhibitors [32,33]. Direct addition into the "sol" is simple way of doping inhibitor into the OlH network. Inorganic inhibitors like cerium nitrate have shown the positive influence on the corrosion protection of aluminum alloys. Most of these inhibitors suppress aluminum corrosion by covering the surface with passive films and by forming complexes with the alloy. However, these inhibitors negatively influence the $\mathrm{pH}$ and hence pot-life of the sol-gel bath $[34,35]$. Organic compounds and their inhibiting action on corrosion of aluminum alloys have been evaluated in the present study. Because of their inhibiting action towards cathodic or anodic process, triazole and thiazole derivatives as well as 8-hydroxyquinoline were studied as potential corrosion inhibitors $[36,37]$. The triazole organic inhibitor in the silane film can react with the copper containing phases and form Cu-triazole complexes thus making the copper unreactive to the corrosive medium. The inhibitor thus gets immobilized at the reactive metal surface and gives a reduction in the cathodic current density [32].

In the present study, a bis-silane type precursor has been synthesized by reaction of epoxy resin and amino silane. OIH films, with and without 2-mercaptobenzothiazole (MBT) as corrosion inhibitor, have been deposited on aluminum alloy test panels by controlled dip-coating application, followed by thermal curing. The corrosion resistance properties of these coatings have been studied by potentiodynamic polarization study (D.C. Polarization), electrochemical impedance spectroscopy (EIS), and accelerated neutral salt-fog test (ASTM B117).

\section{EXPERIMENTAL}

\subsection{Materials}

Glycidoxypropyltrimethoxysilane (GPTMS) and Bis (3trimethoxysilyl-propyl) amine (Dynasylan 1124 ()) were provided by Evonik Industries, USA. Heloxy Modifier $65 \AA$ glycidyl ether of p-tert butyl phenol (GEPTBP) $(E E W=230)$ and epoxy resin (Diglycidyl ether of bis-phenol-A (DGEBA) 
(EPON $828 \AA, E E W=188$ ) were supplied by Momentive, USA. Brulin $815 \mathrm{GD}$, a proprietary detergent, was obtained from Brulin \& company Inc. IMPRESS $\AA$ A6000 thermoset powder coating was supplied from AkzoNobel, and 2mercaptobenzothiazole (MBT) (corrosion inhibitor) and other chemicals and solvents were purchased from Sigma-Aldrich. Aluminum alloy (AA3003-H14) panels were supplied by ACT panels LLC, USA.

\subsection{Methods}

\subsubsection{Corrosion Tests}

\subsubsection{Electrochemical Tests}

The corrosion behavior of the specimens was analyzed using Electrochemical Impedance Spectroscopy (EIS) technique through a Gamry G300 potentiostat connected to a threeelectrode set-up (PTC1) consisting saturated calomel electrode (SCE) as reference electrode, graphite rod as counter electrode, and coated panels as working electrode. For each sample an area of $14.6 \mathrm{~cm}^{2}$ was exposed to $3.5 \%$ $\mathrm{NaCl}$ solution as test electrolyte. EIS was performed in the frequency range of $1-100 \mathrm{kHz}$ using a frequency response analyzer (Echem analyst). DC polarization curves were analyzed using Gamry G300 potentiostat at a scan rate of 1 $\mathrm{mV} / \mathrm{s}$ in the applied potential range from-0.4 to $-1.2 \mathrm{~V}$. The three-electrode set-up (PTC1) and.5\% $\mathrm{NaCl}$ solution as test electrolyte has been used. The data extracted from electrochemical analysis plots represent the average of measurements on three samples.

\subsubsection{Salt Spray Test}

The powder coated samples with an artificial scratch were characterized using Neutral Salt Spray (NSS) test, according to ASTM B117 in order to monitor the loss of adhesion in the cross section and corrosion progress in the cutting edge. The scribes for salt spray test have a length of $10 \mathrm{~mm}$ and the width about $0.1 \mathrm{~mm}$. Each sample was repeated for three times to confirm the repeatability of the results of the experiment and average ratings have been reported.

\subsubsection{Fourier Transform Infrared (FTIR) Spectroscopy}

A Fourier transform infrared spectrometer (Bruker Tensor 27 and Opus 5.0 software) was used in mid-infrared range of 400-4000 cm $\mathrm{cm}^{-1}$, with a resolution of $4 \mathrm{~cm}^{-1}$, for characterization of the chemical structure of the silane precursor and the $\mathrm{OIH}$ film. Approximately $1 \mathrm{mg}$ of sample (cured in $120^{\circ} \mathrm{C}$ ) in powder form is well mixed into 200 to 250 $\mathrm{mg}$ fine $\mathrm{KBr}$ powder and then finely pulverized and put into a pellet-forming die. A force of approximately 8 tons is applied for several minutes to form transparent pellets then pellets have been measured in FTIR mode. The test background also was made with analysis of only $\mathrm{KBr}$ pellet inserted into the sample chamber.

\subsubsection{Morphology of Films}

The surface morphology of the samples was evaluated by using Scanning Electron Microscopy (SEM) Hitachi S 34000N instrument. In order to minimize sample charge and e-beam damage of the samples and increasing the secondary electron emissions, samples were gold deposited by Denton Vacuum instrument before scanning electron microscopy.

\subsection{Synthesis of Epoxy-Silane Precursor}

EPON 828 (16.54 g, EEW=188) and Heloxy Modifier 65 (5.51 $\mathrm{g}, \mathrm{EEW}=230$ ) and anhydrous ethyl alcohol $(40 \mathrm{~g})$ were placed into a three-neck flask attached to a mechanical stirrer, water condenser, heating system (heating mental, thermocouple and temperature controller) and an inlet for dry nitrogen gas. The solution was heated to $50{ }^{\circ} \mathrm{C}$ and bis (3-trimethoxysilylpropyl) amine $(37.9 \mathrm{~g})$ was added drop wise to the epoxy resin solution from an addition funnel for $30 \mathrm{~min}$. After the addition of amine was complete, reaction was continued at $50^{\circ} \mathrm{C}$ for $5 \mathrm{~h}$. The composition for three precursors $\mathrm{A}, \mathrm{B}$ and $\mathrm{C}$ are shown in Table 1.

The completion of reaction was followed by FT-IR spectroscopy, by following disappearance of peak at $915 \mathrm{~cm}$ ${ }^{1}$ corresponding to $\mathrm{C}-\mathrm{O}$ deformation of epoxy ring associated with epoxy group. Silane functionalized epoxy precursor was obtained as clear and low viscosity liquid with solid content of $\sim 60 \%$ by mass. The representative structure of epoxy-silane precursor (Heloxy 65 structure not shown) is shown in Figure 1.

\subsection{Preparation of Sol-Gel Application Bath}

Into a clean and dry $500 \mathrm{ml}$ glass beaker, dry ethyl alcohol and DI water (ratio 2:1 by wt.) were mixed at room temperature using a magnetic stirrer. Glacial acetic acid was then added under stirring to bring $\mathrm{pH}$ of the mixture to $\sim 4.00$ followed by addition of epoxy silane precursor. GPTMS was hydrolyzed in a separate beaker under stirring; with similar bath composition containing ethyl alcohol and DI water and Glacial acetic acid, for $5 \mathrm{~h}$. The final sol-gel application bath was then prepared by mixing slowly under stirring, the

Table 1: Precursor Composition

\begin{tabular}{|c|c|c|c|c|c|}
\hline \multirow{2}{*}{ Precursor } & \multirow{2}{*}{ Ratio DGEBA/GEPTBP } & \multicolumn{3}{|c|}{ Parts by Weight (g) } \\
\cline { 3 - 6 } & & EPON 828 & Heloxy 65 & Ethanol & bis (3-trimethoxysilyl-propyl) amine \\
\hline \hline A & $100 / 0$ & 21.30 & ---38.70 \\
\hline B & $75 / 25$ & 16.50 & 5.50 & 40.00 & 38.00 \\
\hline C & $50 / 50$ & 11.40 & 11.40 & 40.00 & 37.20 \\
\hline
\end{tabular}


hydrolyzed GPTMS solution and epoxy silane precursor solution. Table 2 shows the components and their quantities (g) in the final sol-gel application bath. Mercaptanbenztriazol $(1,2$, and $3 \%$ by mass of bath solids), dissolved in small quantity of acetone, was then added to sol-gel application bath under stirring. After $1 \mathrm{~h}$, test panels were applied by dipcoating method.

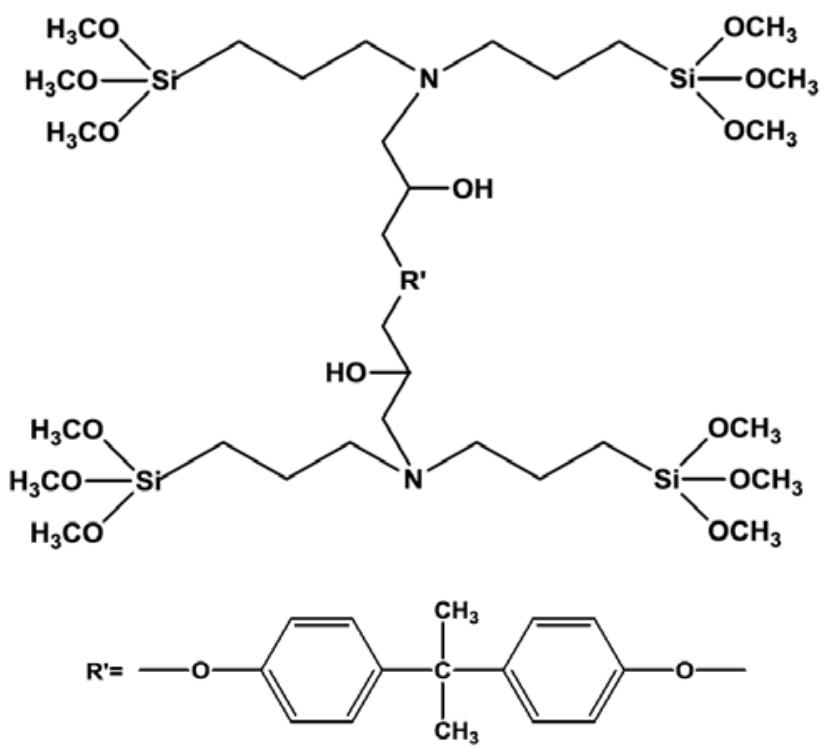

Figure 1: A representative structure of epoxy-silane precursor.

\subsection{Preparation of Test Panels}

Aluminum alloy panels were degreased and chemically etched before application of pretreatments as per the following process. In the first step, panels were scrubbed with a sponge side of Scotch Brite ${ }^{\circledR}$ pad dipped in a 10:1 mixture of tap water and Brulin 815GD at room temperature, followed by tap water rinsing and checking for "break-free" test by immersion in de-ionized water. The test panels then received 5 minutes immersion in the tap water/ Brulin 815 GD (10:1) circulating bath heated to $65^{\circ} \mathrm{C}$, and then rinsed by 10 dunks in tap water immersion, followed by spraying of low pressure de-ionized water. Panels were then immersed in a circulating de-oxidizing bath for 2 minutes, and then 10 dunks immersion in tap water followed by low pressure spray of de-ionized water. Deoxidizing bath contained 35\% butyl alcohol, $25 \%$ isopropyl alcohol, $18 \%$ phosphoric acid, and $22 \%$ de-ionized water (by vol.). Panels were placed vertically in a panel stacker for drying and OIH pretreatments were applied within
$6 \mathrm{~h}$. In order to avoid the variations that may be caused by pretreatment process, all the panels were prepared by the above described method in a single lot.

\subsection{Application of OIH Film}

All pretreatments were applied at room temperature (25-30 ${ }^{\circ} \mathrm{C}$ ) using an automatic dip coater (PTL-200, MTI Corporation), at an immersion/withdrawal speed of 15-17 $\mathrm{cm} /$ minutes, with a residence time of 15-20 seconds. After the application, the panels were placed vertically in a panel stacker for 15 minutes of air drying, followed by 30 minutes of thermal curing in an air circulating oven at $120^{\circ} \mathrm{C}$. Some test panels studied were not only air-dried and not thermally cured. The typical dry-film thickness obtained were $\sim 5-7$ microns, as measured by SEM images.

\subsection{Application of Powder Coating}

A thermosetting epoxy-polyester clear powder coating, as a topcoat, was applied on pre-treated thermally cured as well as air-dried test panels. The powder coating was applied using an electrostatic spray gun (Nordson) using compressed air pressure of 10-15 psi. After application of powder coating, panels were cured in an air-oven at $180^{\circ} \mathrm{C}$ for 30 minutes. The average dry-film thickness of complete coated system was $\sim 70$ microns.

\section{RESULTS AND DISCUSSION}

\subsection{Film Formation}

Silane based OIH films were deposited by a two-step acid catalysed sol-gel process. The first step is hydrolysis of GPTMS and epoxy-silane precursor, wherein the majority of alkoxy silane groups are hydrolyzed to silanol groups (sol) with formation of corresponding alcohol. In the second step, silanol groups are condensed to form siloxane linkages (gel) with formation of water or alcohol as by products. Thus, organic-inorganic hybrid network is formed by complex solgel reactions (Figure 2). It should be noted that that while "sol" formation (step-I) takes place in the application bath, the majority of the "gel" reaction (step-II) occurs on the substrate and requires higher temperature for high extent of completion. Therefore, test panels, after intial air-drying were subjected to thermal curing for $30 \mathrm{~min}$ at $120^{\circ} \mathrm{C}$.

GPTMS has been included in the composition with two-fold intended benefits. GPTMS is an organofunctionalized silane

Table 2: Sol-Gel Application Bath Compositions

\begin{tabular}{|c|c|c|c|c|}
\hline \multirow{2}{*}{ Epoxy silane precursor solution } & Epoxy-silane precursor & Ethanol & DI water & Acetic acid \\
\cline { 2 - 5 } & 20.00 & 50.00 & 25.00 & $\sim 5$ \\
\hline \multirow{2}{*}{ GPTMS solution } & GPTMS & Ethanol & DI water & Acetic acid \\
\cline { 2 - 5 } & 20.00 & 50.00 & 25.00 & $\sim 5$ \\
\hline
\end{tabular}


Journal of Coating Science and Technology, 2016, Volume 3, No. 1

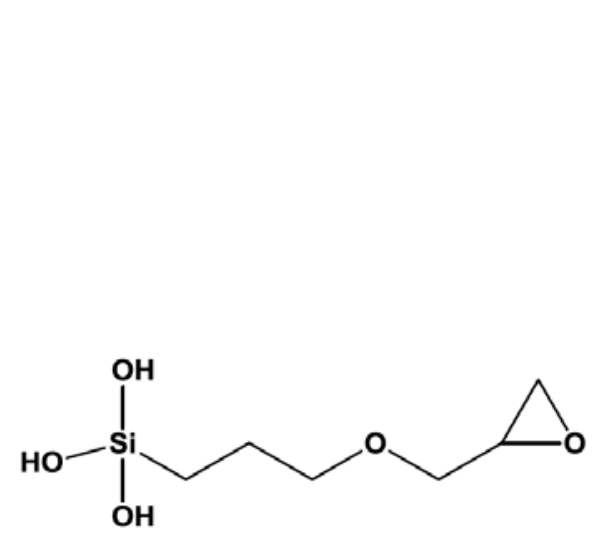

(a)<smiles>OCC(O)CN(CCCN(CCC[Si](O)(O)O)CC(O)C[R]CCC[Si](O)(O)O)CCC[Si](O)(O)O</smiles>

(b)

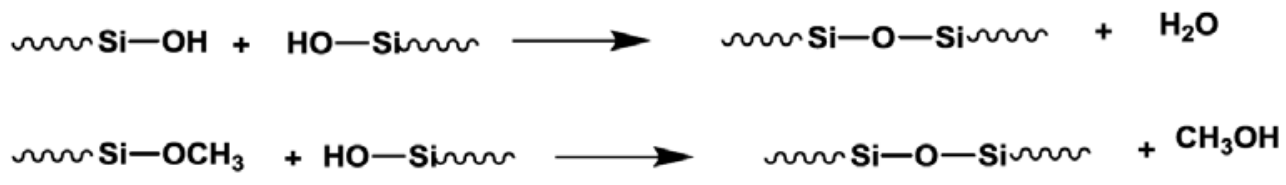

(c)

Figure 2: Representative structures of (a) hydrolyzed GPTMS, (b) hydrolyzed precursor, (c) simplified sol-gel reactions leading to hybrid network formation.

composed of a short carbon backbone with an epoxy functionalized tail and a Si atom substituted with three (-O$\mathrm{CH} 3$ ) groups It is expected to form cross-links through silanol groups and integrate with the epoxy-silane hybrid network. The glycidyl groups of GPTMS present on the OIH network would chemically react with appropriate functional groups of the top coat and hence enhance intercoat adhesion between pretreatment and topcoiat. In the present study, the caroxylic acid groups of the top coat (epoxy-polyester powder coating) would react with the surface glycidyl groups of the pretreatment forming covalent ester linkages, as depicted in Figure 3.

\subsection{Chemical Structure of Precursor}

Epoxy-silane precursor used in this study has been designed with the requirements of solubility in ethanol/water mixture, bath stability, and chemical structure that provides good barrier properties of the cured OIH films. Our attempts to prepare epoxy-silane precursor simply by reaction of DGEBA and bis-(3-trimethoxysilyl-propyl) amine (amino silane) resulted in poor bath stability during the initial experimental trials, and it was found necessary to use other monofunctional epoxide compound/s in conjunction with DGEBA to increase the bath stability time for efficient processing. In the synthesis of precursor, the epoxy compounds were reacted,

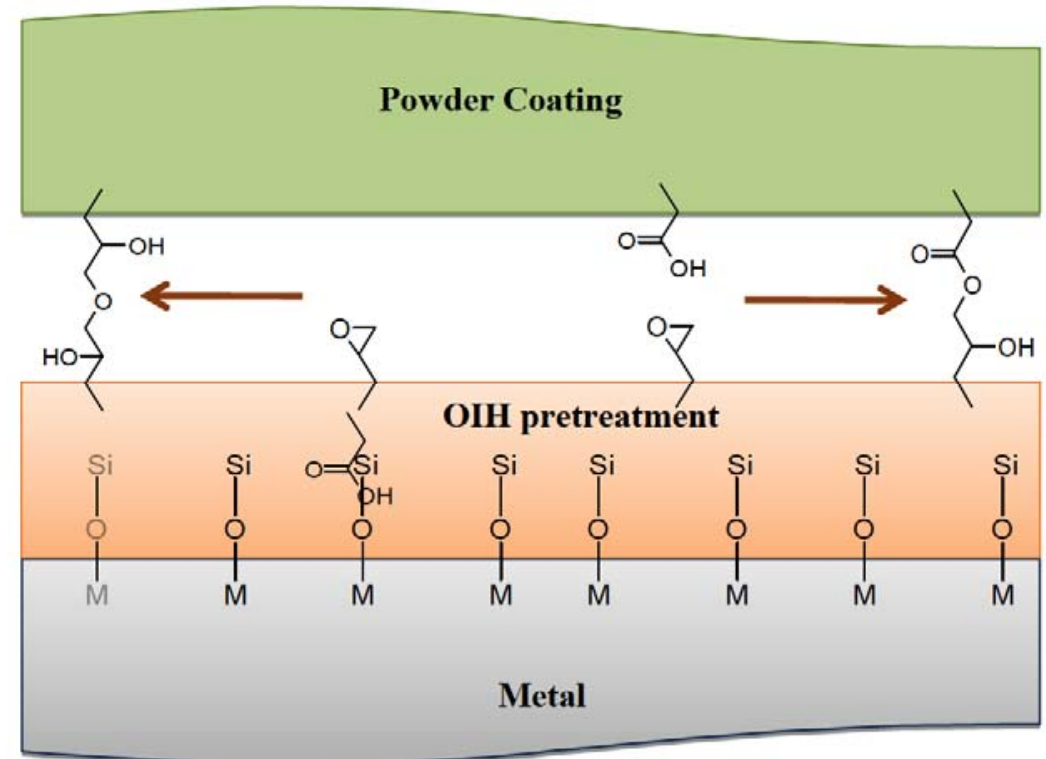

Figure 3: Interaction of $\mathrm{OIH}$ film with top coat and metal. 


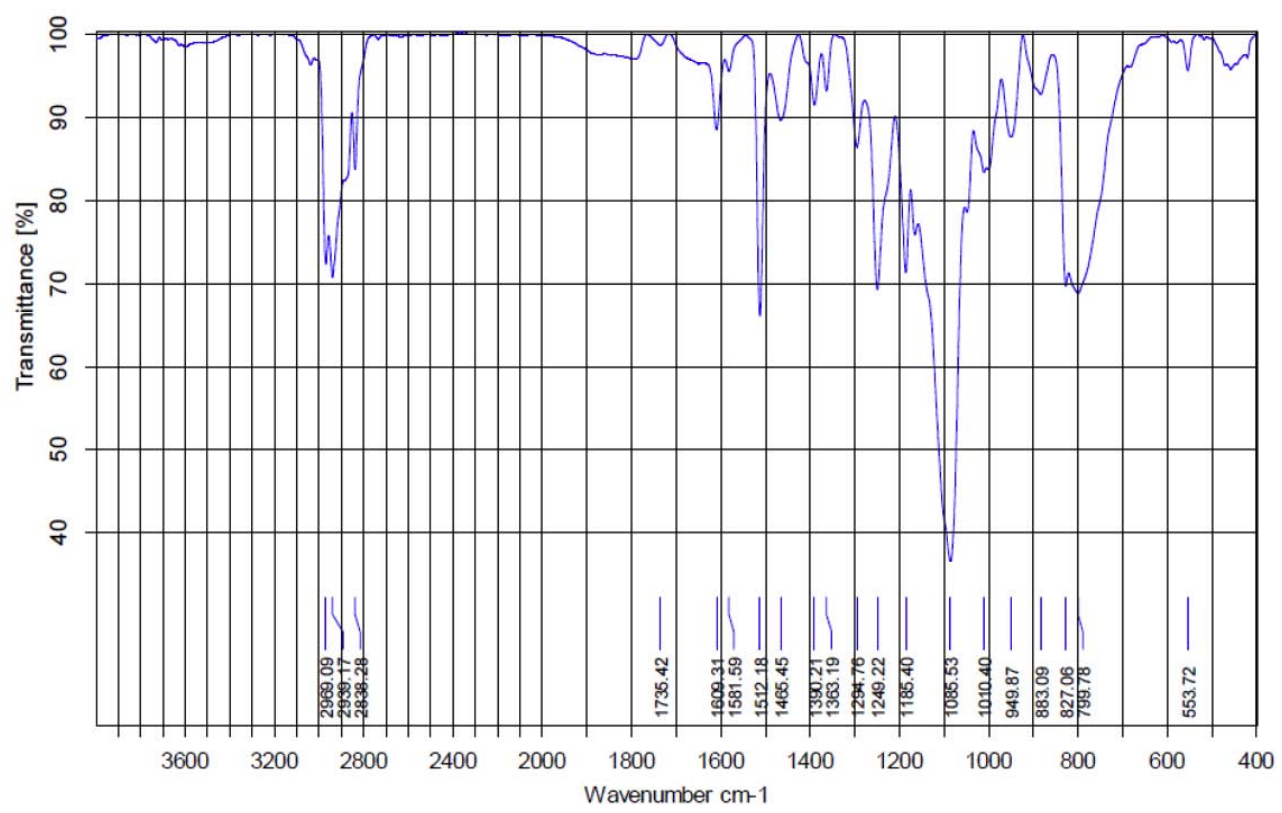

Figure 4: FTIR spectra epoxy-silane precursor.

in stoichiometric ratio, with amino-silane in presence of ethanol as a solvent. Reaction was monitored by following amine and epoxy content of the reaction mixture using FT-IR spectroscopic technique. FT-IR spectrum of epoxy-silane precursor is shown in Figure 4. The absence of any absorption peak at near $915 \mathrm{~cm}^{-1}$ corresponding to C-O deformation of epoxy ring confirms the consumption of all epoxy groups. Absence of $\mathrm{N}-\mathrm{H}$ stretching peak around 3250 $\mathrm{cm}^{-1}$ to $3400 \mathrm{~cm}^{-1}$ revealed that secondary amine groups of amino-silane have been reacted completely. A strong absorption peak at $1085 \mathrm{~cm}^{-1}$ corresponding to Si-O linkage is evident of presence of methoxy silane functions (Table 3 ).

Table 3: Infrared Characteristic Absorption Bands of Epoxy Silane Precursor

\begin{tabular}{|c|c|}
\hline Functional group & Wave number $\left(\mathbf{c m}^{-1}\right)$ \\
\hline \hline Si-O & 1085 \\
\hline C-H Aromatic & $2939-2969$ \\
\hline C-H Aliphatic & 2838 \\
\hline O-CH ${ }_{3}$ Asymmetric vibration & $799-1249$ \\
\hline C=C Aromatic & 1512 \\
\hline
\end{tabular}

\subsection{Bath Pot-Life}

The term of bath pot-life refers to the longest time that bath solution remains fluid and usable by dip application method. In the present study the silane-precursor $A$ which is made with only DGEBA and Bis (3-trimethoxysilyl-propyl) amine, with $12 \mathrm{Si}^{-\mathrm{OCH}_{3}}$ groups showed very short bath pot-life of only a few minutes. Therefore, a part of DGEBA was replaced with lower functional epoxide, GEPTBP, so that average silane functionality of the precursor can be reduced. The precursors B and C replacing 25 wt. $\%$ and 50 wt. \% of
DGEBA by GEPTBP showed marginal improvement in the bath pot-life. In order to facilitate efficient application, bath pot-life were further improved by addition of GPTMS (prehydrolyzed), as shown in Figure 5. Bath pot-life mainly depends on the nature of silane precursor, silane functionality (number of Si-OR groups), $\mathrm{pH}$, alcohol/water ratio, temperature and concentration of precursor [38-41]. These factors can be controlled to balance bath pot-life and performance of OIH films. For the precursor $\mathrm{C}$, when a part of DGEBA was replaced with lower functional epoxy, silane functionality reduced and bath stability time had been increased tremendously to one week. This composition has been used for further study.

\subsection{Morphology of Films}

Prior to the investigation of corrosion protection the surface morphology and appearance of the different pre-treatments were characterized by scanning electron microscope (SEM). Figure 6 shows representative SEM images of bare aluminum alloy surface (Figure 6a) and a pretreated surface (Figure $6 \mathbf{b}$ ). It is evident that surface of the bare aluminum alloy shows roughness due to the inter-metallic particles, whereas the pretreated surface shows very smooth topography showing uniform deposition of sol-gel hybrid film. More important, however, is to verify if the pre-treatment is able to give sufficient protection properties. For this purpose, electrochemical impedance spectroscopy measurements were performed.

\subsection{Electrochemical Tests}

\subsubsection{Polarization}

The results of the potentiodynamic polarization measurements of $\mathrm{OlH}$ pretreatment containing 3\% inhibitor, 


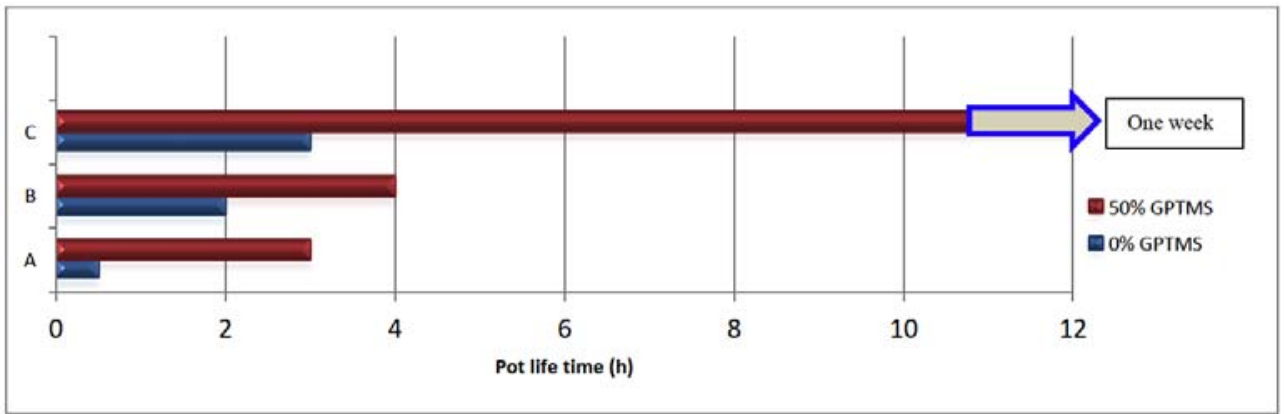

Figure 5: Observed bath pot-life for different precursors.
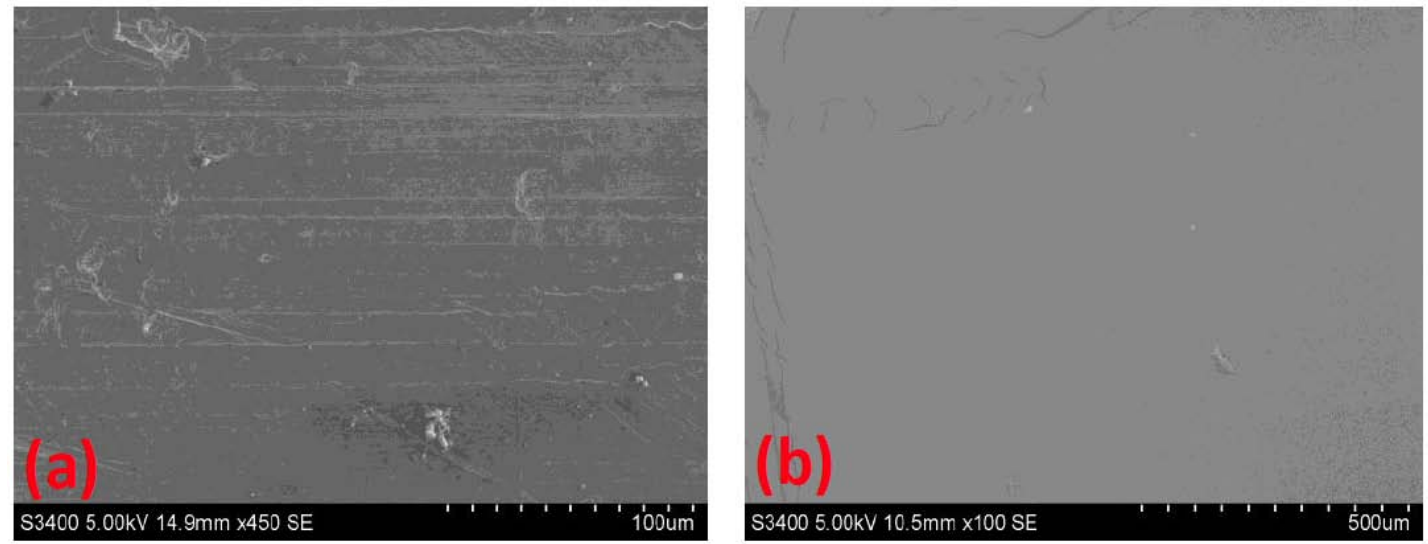

Figure 6: SEM images of aluminum alloy substrate (a) blank and (b) pretreated surfaces from $25 \%$ solid content sol-gel bath.

after one week of exposure to electrolyte, are shown in Figure 7. The appropriate parameters determined after Tafel fitting are given in Table 4. As expected, the $\mathrm{OlH}$ pretreated samples showed good corrosion protection as indicated by their lower $I_{\text {corr }}$ compared to that for bare substrate.

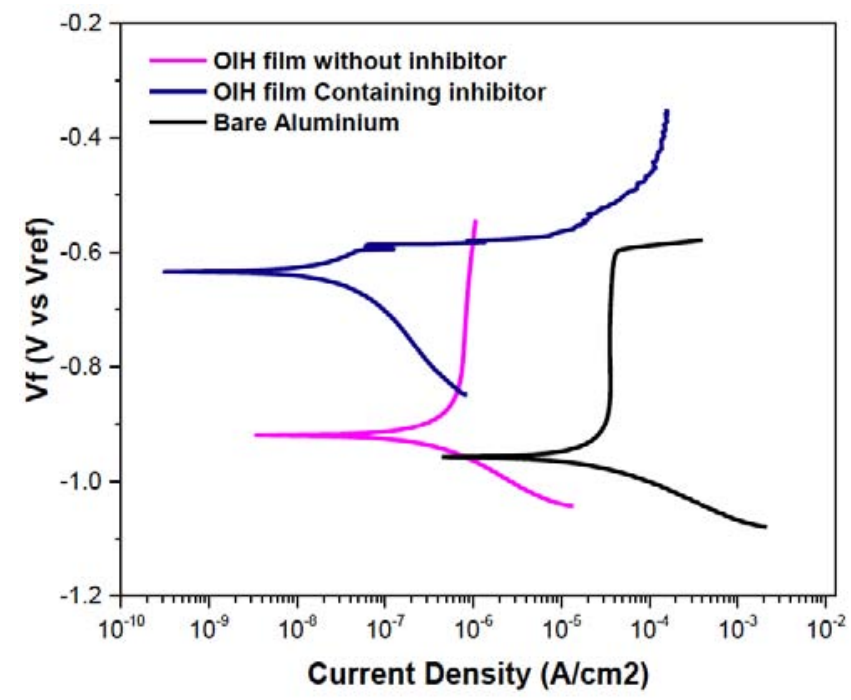

Figure 7: Comparison of polarization data for $\mathrm{OlH}$ films with and without inhibitor and bare test panel after one week exposure to $3.5 \mathrm{wt} \% \mathrm{NaCl}$ solution.

The DC polarization curves of $\mathrm{OlH}$ films with varying concentration of MBT are presented in Figure 8. Addition of small amounts of this organic inhibitor to the pretreatment shifted the $E_{\text {corr }}$ to cathodic potentials, indicating that this inhibitor act as cathodic inhibitor by suppressing the cathodic reduction reaction. The tests were carried out after exposure to $3.5 \% \mathrm{NaCl}$ solution for $24 \mathrm{~h}$.

Table 4: Results of the Potentiodynamic Polarization Measurements for OIH Pretreatments with and without Inhibitor and Bare Panels after One Week Exposure to $3.5 \mathrm{wt} \% \mathrm{NaCl}$ after Tafel Fit

\begin{tabular}{|c|c|c|}
\hline Sample Type & $\mathrm{I}_{\text {corr }}\left(\mathbf{A} / \mathbf{c m}^{2}\right)$ & $E_{\text {corr }}(\mathbf{m V}$ vs. SCE $)$ \\
\hline \hline Bare AA 3003H14 & $35.70 \times 10^{-6}$ & -957.0 \\
\hline OIH pretreatment-0\% inhibitor & $742 \times 10^{-9}$ & -919 \\
\hline OIH pretreatment-3\% inhibitor & $27.9 \times 10^{-9}$ & -631 \\
\hline
\end{tabular}

As can be seen from Table $\mathbf{5}$, the corrosion current $\left(I_{\text {corr }}\right)$ values for inhibitor-doped $\mathrm{OIH}$ films are significantly lower than that without inhibitor. Furthermore, with increasing inhibitor level to $2 \%$ and above, there is an order of magnitude increase in polarization resistance and drop in corrosion current density. This clearly shows the effectiveness of MBT as corrosion inhibitor in $\mathrm{OlH}$ systems. Figure 9 shows images of the test panels after 20 days exposure to $3.5 \% \mathrm{NaCl}$ solution. Again, the corrosion inhibitor (MBT)-doped sample showed little or no corrosion whereas that without MBT showed significant corrosion, discoloration and pit formation. These results indicate that inhibitor 
effectively protect the aluminum alloy in corrosive environment for extended period of time.

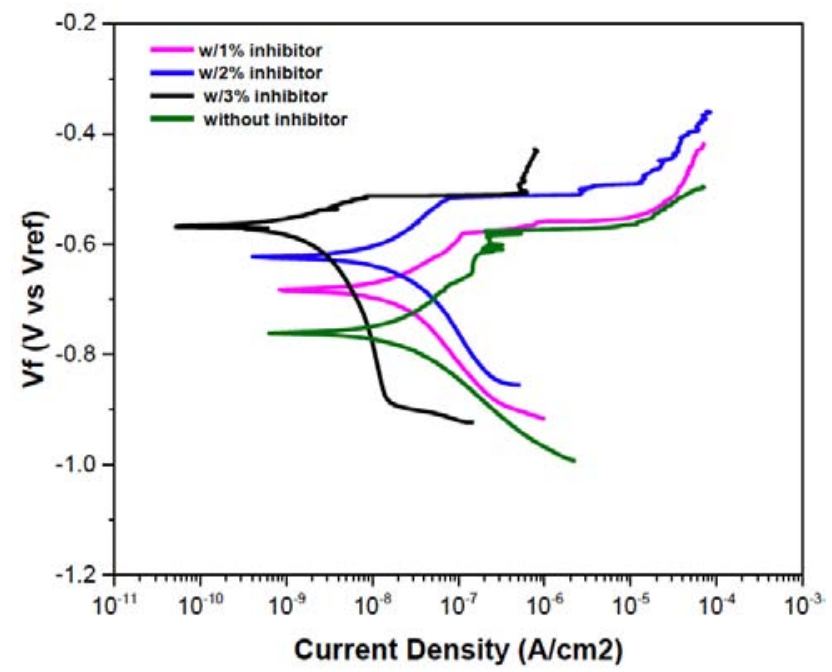

Figure 8: Potentiodynamic scans of pretreated panels without inhibitor and with $(1,2$, and $3 \%)$ inhibitor after $24 \mathrm{~h}$ exposure to $3.5 \mathrm{wt} \% \mathrm{NaCl}$ solution.

Table 5: Numerical Results of DC Polarization Tests Obtained from the Fitting of the Tafel Plots

\begin{tabular}{|c|c|c|}
\hline Sample Type & $\mathbf{I}_{\text {corr }}\left(\mathbf{A} / \mathbf{c m}^{2}\right)$ & $E_{\text {corr }}(\mathbf{m V}$ vs. SCE) \\
\hline \hline OIH Pretreatment (0\% inhibitor) & $26.80 \mathrm{nA}$ & $-761.0 \mathrm{mV}$ \\
\hline OIH Pretreatment 1\%inhibitor & $8.280 \mathrm{nA}$ & $-675.0 \mathrm{mV}$ \\
\hline OIH Pretreatment 2\%inhibitor & $4.810 \mathrm{nA}$ & $-601 \mathrm{mV}$ \\
\hline OIH Pretreatment 3\%inhibitor & $2.340 \mathrm{nA}$ & $-551.0 \mathrm{mV}$ \\
\hline
\end{tabular}

In general, coatings reduce metal corrosion by two mechanisms: passive corrosion protection and active corrosion protection [30]. Passive protection is normally provided by a barrier film that prevents contact of corrosive species with the metal surface and therefore hinders corrosion process. However, when a defect is formed in the barrier layer, the coating cannot stop corrosion in the damaged area. In the active corrosion protection it employs inhibitive species that can decrease corrosion activity. An important point is that both strategies must be used together to adequately protect the metallic substrate [42]. The incorporation of organic corrosion inhibitors into hybrid films has been realized as a result of physical entrapment of the inhibitor within the $\mathrm{OIH}$ film at the stage of film formation and cross-linking [36].

\subsubsection{EIS Study}

Electrochemical impedance measurements were carried out to characterize the cured $\mathrm{OIH}$ films. Figures 10 and 11 show the Bode plots after $24 \mathrm{~h}$ and one week of immersion in 3.5wt $\% \mathrm{NaCl}$ solution, respectively. The barrier properties of the thermally cured films show the best results, probably due to the dense and stable Si-O-Si network. On the other hand, ambient temperature cured sample showed a decrease in low frequency impedance modulus indicating poor barrier properties.

It is important to recognize that when exposed to aggressive corrosive environment, films that provide merely barrier protection are not adequate for long term protection. The presence of inhibitor in such films can hinder the progress of corrosion as shown in Figure 11. In the high frequency range, the magnitude of impedance of the inhibitor-doped $\mathrm{OlH}$ film has been found to be one order of magnitude higher than that for pretreatment without inhibitor. The plateau height of Bode curve at the low frequency region can be associated with the corrosion resistance of a sample. The magnitude of the impedance of the inhibitor-doped $\mathrm{OIH}$ film is found to be at least one half-order of magnitude higher than that without inhibitors, indicating higher corrosion resistance for the pretreatments containing inhibitor.

The quantification of characteristic values such as resistance or capacitance of particular elements of the pretreatment system was carried out by numerical fitting of the impedance spectra. Appropriate equivalent circuits based on the physicochemical model of the corrosion process were used to study different stages of film degradation and corrosion related phenomena. The equivalent circuit used in this study is shown in Figure 12 [43].

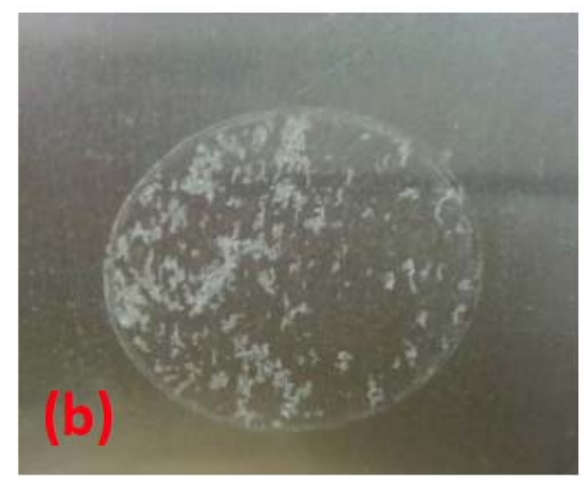

Figure 9: Pretreated panels (a) with and (b) without organic inhibitor after 20 days exposure to $3.5 \mathrm{wt} \% \mathrm{NaCl}$ solution. 


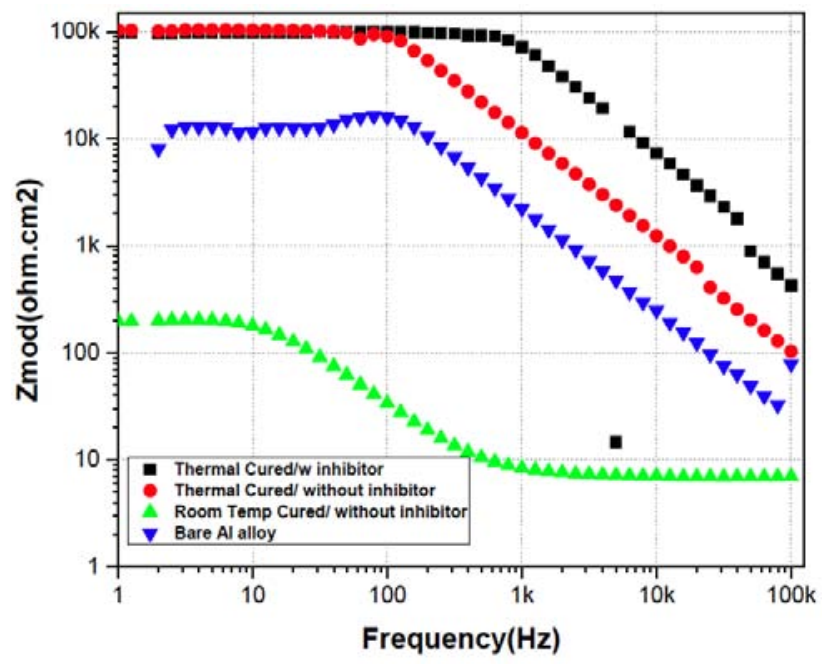

Figure 10: Bode modulus after $24 \mathrm{~h}$ immersion in $3.5 \mathrm{wt} . \% \mathrm{NaCl}$.

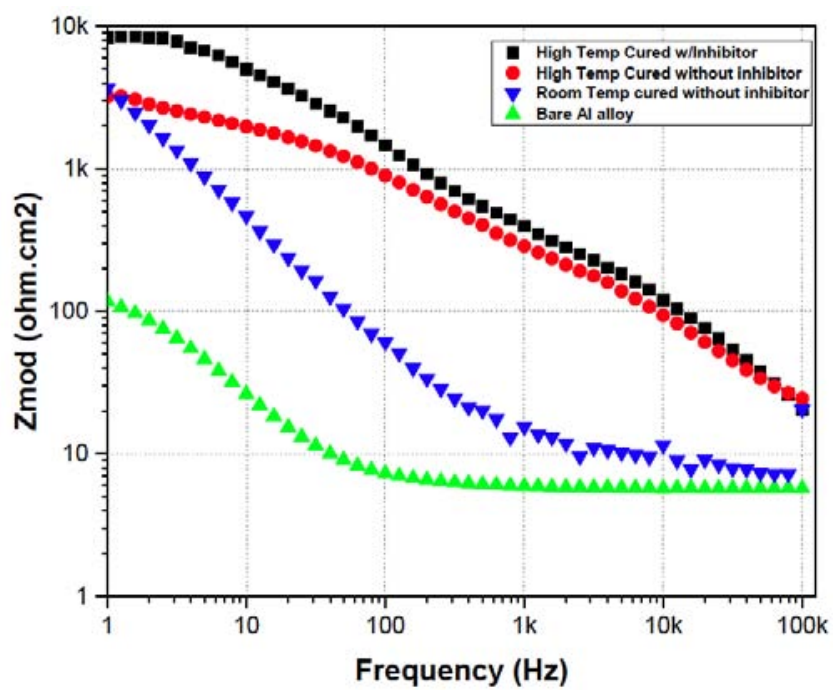

Figure 11: Bode modulus after one week of immersion in $3.5 \mathrm{wt} . \%$ $\mathrm{NaCl}$.

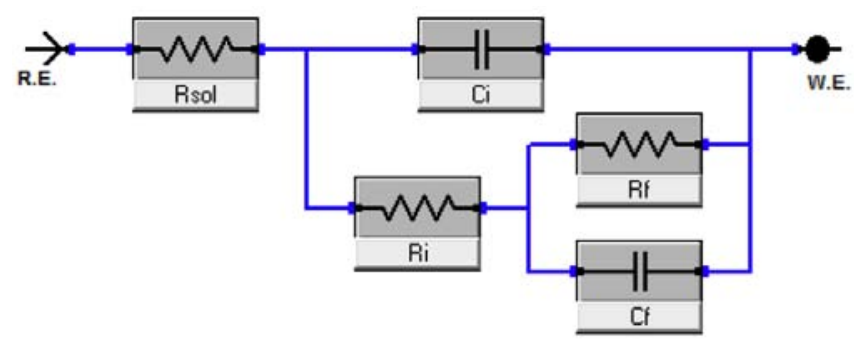

Figure 12: Equivalent circuit used to fit the experimental EIS data (R.E.: reference electrode, W.E.: working electrode, C: Capacitance, R: resistance, sol: solution, f: film, i: interface).

$R_{\text {sol }}$ is the resistance of the solution, $R_{f}$ and $R_{i}$ are the pore resistance and charge transfer resistance of $\mathrm{OlH}$ film respectively. $\mathrm{C}_{\mathrm{f}}$ and $\mathrm{C}_{\mathrm{i}}$ are the capacitance and double layer capacitance of $\mathrm{OlH}$ films respectively. Figures 13 and 14 show the evolution of the resistance and capacitance for the $\mathrm{OIH}$ films respectively, during immersion in $3.5 \mathrm{wt} \% \mathrm{NaCl}$ solution. These figures reveal that protective properties of the $\mathrm{OlH}$ films are dependent on the incorporated inhibitor. These results represent the average of 3 measurements. The plots show the highest resistance $R_{f}$ at the beginning of immersion in corrosive solution, and the fastest decrease of the pore resistance occurs during the first $24 \mathrm{~h}$ of immersion, which can be explained by penetration of corrosive species like water and chloride ions through the pores. Higher resistance of $\mathrm{OlH}$ films containing corrosion inhibitors reveals the suppression of corrosion of substrate due to lower concentration of the active corrosion sites. The capacitance raise indicates film degradation that may result from a decrease of the layer thickness or increase of the dielectric constant due to water uptake of film. The capacitance of film contains corrosion inhibitor also shows an increase; however, it is much slower in time. Probably due to a very low film thickness, the change in film capacitance which is directly related to film water uptake is not noticeable.

The parameters for the ambient temperature cured and thermally cured films have been analyzed in order to assess the effect of curing temperature on the corrosion protection properties (Table 6). The capacitance of the $\mathrm{OlH}$ films cured at $120{ }^{\circ} \mathrm{C}$ (system A) is found to be lower than that of ambient temperature cured (system B) after one-week immersion in the $3.5 \% \mathrm{NaCl}$ solution. In general, the capacitance of a dielectric film depends on the amount of absorbed water. The data exhibits that room temperature cured film uptake water faster than thermally cured films. Thermal curing produces a stable and compact hybrid film due to higher crosslink density which decreases the permeability of the film toward water molecule and corrosive species. This trend can also be seen for capacitance at the interface of film and substrate. $R_{f}$ characterizes the crack ability and porosity of the hybrid film. The data pertaining to $R_{f}$ and $R_{i}$ show that the thermally cured film (system A) has higher pore and interface resistance compared to that cured at ambient temperature.

\subsection{Salt Spray Test}

In order to evaluate the capability of the OIH films to provide good inter-coat adhesion between the pretreatment and the top coat, the pretreated samples were coated with a clear thermoset powder coating. We also investigated if the thermal curing of $\mathrm{OlH}$ films, prior to application of powder coating, affects the inter-coat adhesion between pretreatment and powder coating films. An epoxy-polyester powder coating was applied on both air-dried and thermally cured $\mathrm{OIH}$ pretreated samples. After application of powder coatings, test panels were cured at $180 \mathrm{C}$ for $30 \mathrm{~min}$. in an air-circulated oven. These test panels were scribed and then subjected to neutral salt spray test up to $2000 \mathrm{~h}$. The images of the test panels after salt spray test exposure for varying length of time are shown in Figures 15-17. After the exposure, the test panels were observed and rated for their corrosion performance on a OP-10P scale (scale developed internally), with $\mathrm{OP}$ being very poor and $10 \mathrm{P}$ being highest corrosion resistance. 


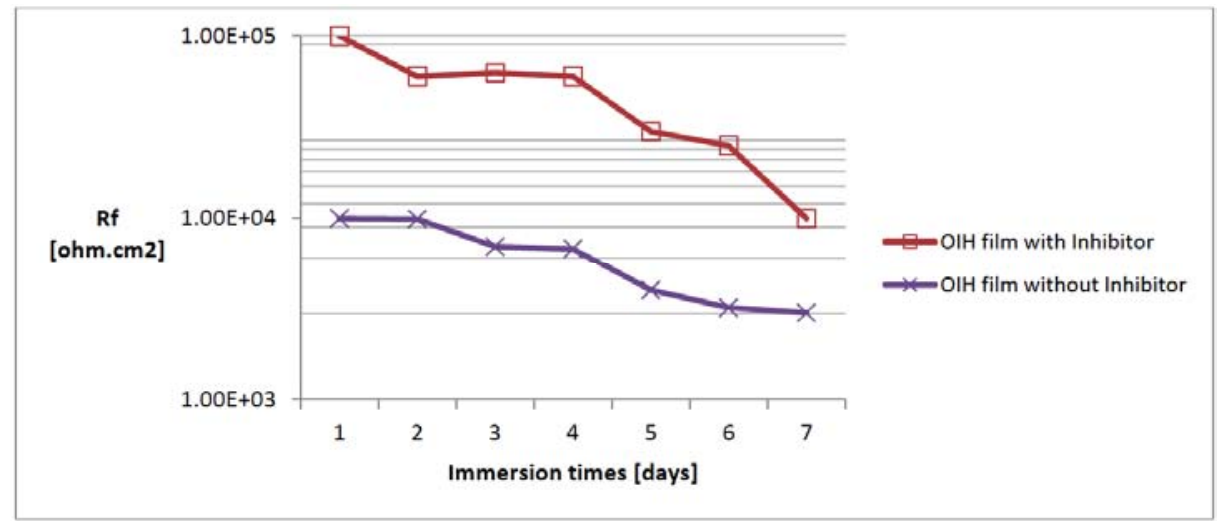

Figure 13: Evolution of the resistance $\mathrm{R}_{\mathrm{f}}$ of $\mathrm{OIH}$ films during immersion in $3.5 \mathrm{wt} \% \mathrm{NaCl}$ solution.

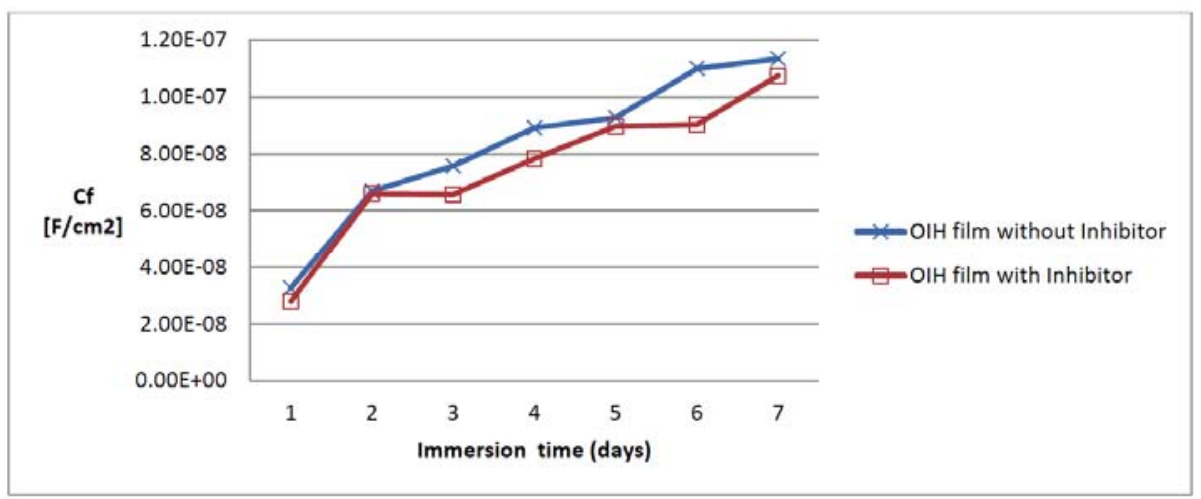

Figure 14: Evolution of the capacitance $\mathrm{C}_{\mathrm{f}}$ of $\mathrm{OlH}$ films during immersion in $3.5 \mathrm{wt} \% \mathrm{NaCl}$ solution.

Table 6: Numerical Data Obtained from the Fitting of Equivalent Electrical Circuit after One Week Immersion in $3.5 \mathrm{wt} \% \mathrm{NaCl}$

\begin{tabular}{|c|c|c|c|c|}
\hline Treatment & $\begin{array}{c}\mathbf{R}_{\mathbf{f}} \\
\text { ohm.cm }\end{array}$ & $\begin{array}{c}\mathbf{R}_{\mathbf{i}} \\
\text { ohm.cm }\end{array}$ & $\begin{array}{c}\mathrm{C}_{\mathrm{f}} \\
\mathrm{F} / \mathrm{cm}\end{array}$ & $\begin{array}{c}\mathrm{C}_{\mathrm{i}} \\
\mathrm{F}^{\mathrm{F} / \mathrm{cm}}{ }^{2}\end{array}$ \\
\hline A: Thermal cured OIH film & $\begin{array}{l}350.3 \\
\text { (std }=0.9)\end{array}$ & $\begin{array}{c}7.26 \times 10^{+2} \\
(\text { std }=0.7)\end{array}$ & $\begin{array}{c}676 \times 10^{-9} \\
(\text { std }=0.6)\end{array}$ & $\begin{array}{c}37.68 \times 10^{-9} \\
\text { (std }=0.8)\end{array}$ \\
\hline B: Room Temperature cured $\mathrm{OlH}$ film & $\begin{array}{l}3.863 \\
\text { (std=0.5) }\end{array}$ & $\begin{array}{l}2.398 \\
\text { (std=0.5) }\end{array}$ & $\begin{array}{c}3169 \times 10^{-9} \\
(\mathrm{std}=0.6)\end{array}$ & $\begin{array}{c}57.46 \times 10^{-9} \\
(\text { std }=0.9)\end{array}$ \\
\hline
\end{tabular}

The ambient temperature cured OIH pretreated samples showed clearly visible corrosion and film detachment, especially near the scribed region. However, thermally cured samples showed much higher corrosion protection, with only a few corrosion spots (Figures 15 and 16). This observation clearly shows that air-dried pretreatments did not form dense
OIH network (insufficient cure extent) and hence could not provide good corrosion resistance, compared to the thermally cured pretreatments.

The results of salt-spray test also provided important information about the effectiveness of the MBT as corrosion

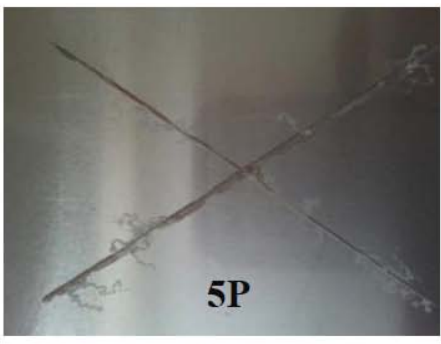

(a)

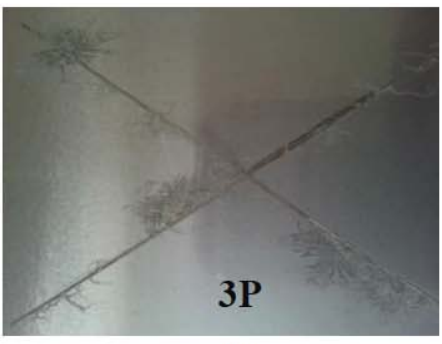

(b)

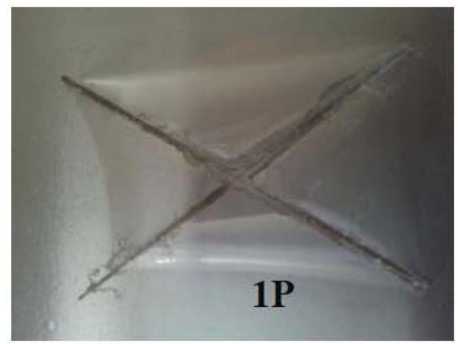

(c)

Figure 15: Powder coated room temperature cured OIH samples without inhibitor after (a) $500 \mathrm{~h}$, (b) $1000 \mathrm{~h}$, and (c) $2000 \mathrm{~h}$. 


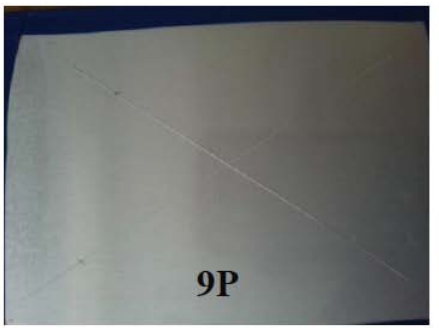

(a)

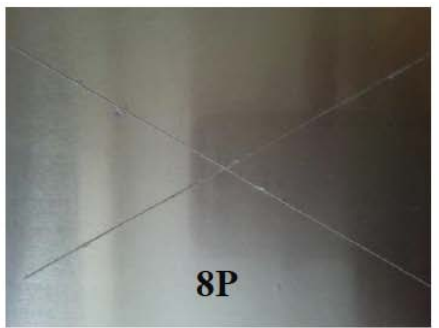

(b)

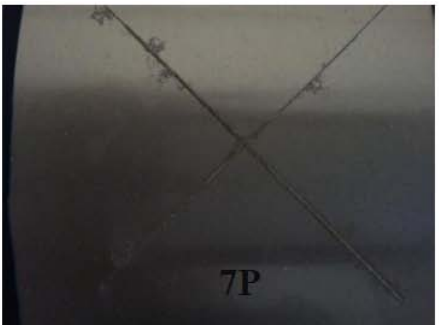

(c)

Figure 16: Powder coated thermal cured OIH samples without inhibitor after (a) $500 \mathrm{~h}$, (b) $1000 \mathrm{~h}$, and (c) $2000 \mathrm{~h}$.

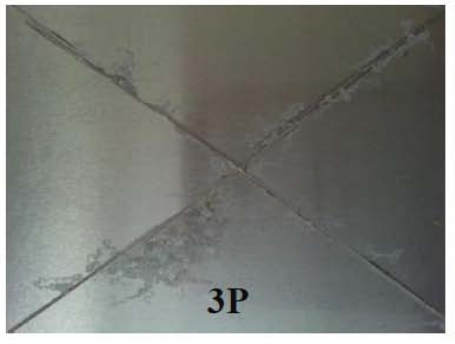

(a)

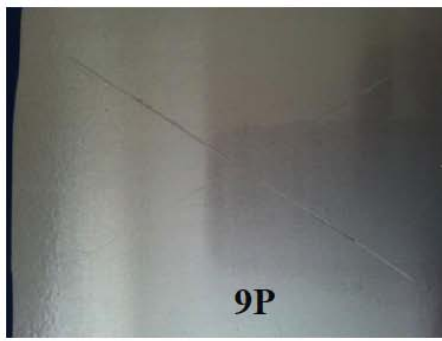

(b)

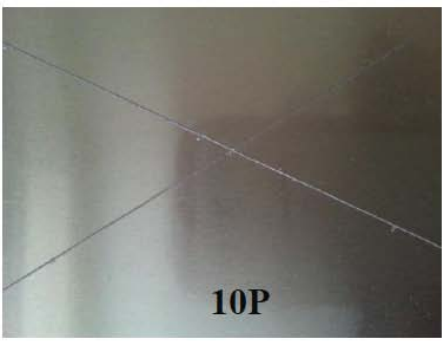

(c)

Figure 17: Powder coated (a) room temperature cured OIH film containing inhibitor, (b) thermal cured OlH film containing inhibitor (c) Chromated after $1000 \mathrm{~h}$.

inhibitor. The $\mathrm{OlH}$ films without inhibitors show the first corrosion signs after $500 \mathrm{~h}$ exposure in salt spray test for the ambient temperature cured samples and after $1000 \mathrm{~h}$ for thermal cured ones. The further corrosion spots appeared after $1000 \mathrm{~h}$ exposure and rapidly accelerated then onward up to $2000 \mathrm{~h}$. The presence of MBT is believed to inhibit the propagation of the corrosion processes up to $2000 \mathrm{~h}$ exposure. The chromate pretreated test panel was also exposed to salt spray as a control (Figure 17). The chromate conversion coatings, as expected, showed the highest corrosion protection, with rating of $10 \mathrm{P}$.

\section{CONCLUSION}

In this study corrosion protection performances of the chromate-free sol-gel derived $\mathrm{OIH}$ pretreatments based on epoxy-silane precursor have been evaluated. The composition and hence functionality of the precursor has been found to be an important factor affecting bath pot-life. The results of the electrochemical study showed good barrier properties of $\mathrm{OlH}$ films, especially when cured at $120{ }^{\circ} \mathrm{C}$. Curing is believed to lead to the formation of a dense and compact $\mathrm{OIH}$ film with improved barrier properties. In addition, these OIH films when loaded with optimum amount of inhibitor (MBT) provide synergistic improvement in corrosion resistance.

\section{ACKNOWLEDGEMENTS}

Authors gratefully acknowledge Michigan Initiative for Innovation and Entrepreneurship (MIIE) for this commercialization grant. Authors would also like to thank
Diversified Chemical Technologies, Inc. Detroit, MI for collaboration and supporting this research.

\section{REFERENCE}

[1] Schweitzer PA, Ed. Corrosion and corrosion protection handbook 2nd ed., rev. and expanded. New York: M. Dekker, 1989.

[2] Schweitzer PA. Corrosion engineering handbook. atmospheric and media corrosion of metals, 2nd ed. Boca Raton: CRC Press 2007

[3] Gilroy D, Eddowes PJ, Dalrymple IM, et al. Techniques for assessing the protective properties of chromated conversion coatings-part I: aluminum. Met Finish 1996; 94: 26-30. http://dx.doi.org./10.1016/0026-0576(96)85145-2

[4] Bonnel K, Le Pen C, Pébère N. E.I.S. characterization of protective coatings on aluminium alloys. Electrochimica Acta 1999; 44: 4259-67. http://dx.doi.org./10.1016/S0013-4686(99)00141-3

[5] Zhang $X$, van den Bos $C$, Sloof WG, Hovestad A, Terryn $H$, de Wit JHW."Comparison of the morphology and corrosion performance of $\mathrm{Cr}(\mathrm{VI})$ - and $\mathrm{Cr}(\mathrm{III})$-based conversion coatings on zinc. Surf Coat Technol 2005; 199: 92-104.

http://dx.doi.org./10.1016/i.surfcoat.2004.12.002

[6] Liu Y, Feng Z, Walton J, Thompson GE, Skeldon P, Zhou X Comparison of the behaviours of chromate and sol-gel coatings on aluminium. Surf Interface Anal 2013; 45: 1446-51. http://dx.doi.org./10.1002/sia.5206

[7] Van Ooij W, VanZhu D, Stacy M, et al. Corrosion protection properties of organofunctional silanes-an overview. Tsinghua Sci Techno 2005; 10: 639-64.

http://dx.doi.org./10.1016/S1007-0214(05)70134-6

[8] Crawmer D. OSHA hexavalent chromium regulation. Adv Mater Process 2006; 164: 62-75. http://go.galegroup.com/ps/i.do?id= GALE\%7CA150656269\&v=2.1\&u=lom emichu\&it=r\&p=ITOF\&sw=w\& asid=f54169527acee $5 \mathrm{fe} 589 \mathrm{c} 6363 \mathrm{ab} 6 \mathrm{acba8}$

[9] Pirhady Tavandashti N, Sanjabi S, Shahrabi T. Corrosion protection evaluation of silica/epoxy hybrid nanocomposite coatings to AA2024. Prog Org Coat 2009; 65: 182-6. http://dx.doi.org./10.1016/i.porgcoat.2008.10.010

[10] Metroke TL, Gandhi JS, Apblett A. Corrosion resistance properties of ormosil coatings on 2024-T3 aluminum alloy. Prog Org Coat 2004; 50: 231-46.

http://dx.doi.org./10.1016/j.porgcoat.2004.03.001 
[11] Twite RL, Bierwagen GP. Review of alternatives to chromate for corrosion protection of aluminum aerospace alloys. Prog Org Coat 1998; 33: 91-100.

http://dx.doi.org./10.1016/S0300-9440(98)00015-0

[12] Bierwagen G, Brown R, Battocchi D, Hayes S. Active metal-based corrosion protective coating systems for aircraft requiring no-chromate pretreatment. Prog Org Coat 2010; 67: 195-208. http://dx.doi.org./10.1016/i.porgcoat.2009.10.031

[13] Kakde V, Mannari V. Advanced chrome-free organic-inorganic hybrid pretreatments for aerospace aluminum alloy 2024-T3-application of novel bis-ureasil sol-gel precursors. J Coat Technol Res 2009; 6: 201-11. http://dx.doi.org/10.1007/s11998-008-9142-4

[14] Feng Z, Liu Y, Thompson GE, Skeldon P. Sol-gel coatings for corrosion protection of 1050 aluminium alloy. Electrochimica Acta 2010; 55: 3518-27.

http://dx.doi.org./10.1016/i.electacta.2010.01.074

[15] Conde A, Durán A, de Damborenea JJ. Polymeric sol-gel coatings as protective layers of aluminium alloys. Prog Org Coat 2003; 46: 28896.

http://dx.doi.org./10.1016/S0300-9440(03)00014-6

[16] Romano A-P, Fedel M, Deflorian F, Olivier M-G. Silane sol-gel film as pretreatment for improvement of barrier properties and filiform corrosion resistance of 6016 aluminium alloy covered by cataphoretic coating. Prog Org Coat 2011; 72: 695-702. http://dx.doi.org./10.1016/j.porgcoat.2011.07.012

[17] Serra A, Ramis $X$, Fernández-Francos $X$. Epoxy sol-gel hybrid thermosets. Coatings 2016; $6: 8$.

http://dx.doi.org/10.3390/coatings6010008

[18] Ciriminna R, Fidalgo A, Pandarus V, Béland F, Ilharco LM, Pagliaro $M$. The sol-gel route to advanced silica-based materials and recent applications. Chem Rev 2013; 113: 6592-620. http://dx.doi.org./10.1021/cr300399c

[19] Davis SR, Brough AR, Atkinson A. Formation of silica/epoxy hybrid network polymers. J Non-Cryst Solids 2003; 315: 197-205. http://dx.doi.org./10.1016/S0022-3093(02)01431-X

[20] Fedel M, Olivier M, Poelman M, Deflorian F, Rossi S, Druart M-E. Corrosion protection properties of silane pre-treated powder coated galvanized steel. Prog Org Coat 2009; 66: 118-28. http://dx.doi.org./10.1016/j.porgcoat.2009.06.011

[21] Palomino LM, Suegama PH, Aoki IV, Fatima Montemor M, De Melo HG. Electrochemical study of modified non-functional bis-silane layers on Al alloy 2024-T3. Corros Sci 2008; 50: 1258-66. http://dx.doi.org./10.1016/j.corsci.2008.01.018

[22] Palanivel V, Zhu D, van Ooij WJ. Nanoparticle-filled silane films as chromate replacements for aluminum alloys. Prog Org Coat 2003; 47: 384-92.

http://dx.doi.org./10.1016/j.porgcoat.2003.08.015

[23] Zhu D, van Ooij WJ. Corrosion protection of AA 2024-T3 by bis-[3(triethoxysilyl)propyl]tetrasulfide in sodium chloride solution.: Part 2: mechanism for corrosion protection. Corros Sci 2003; 45: 2177-97. http://dx.doi.org./10.1016/S0010-938X(03)00061-1

[24] Song J, Van Ooij WJ. Bonding and corrosion protection mechanisms of $\mathrm{Y}$-APS and BTSE silane films on aluminum substrates. J Adhes Sci Technol 2003; 17: 2191-221. http://dx.doi.org./10.1163/156856103772150788

[25] Chruściel JJ, Leśniak E. Modification of epoxy resins with functional silanes, polysiloxanes, silsesquioxanes, silica and silicates. Prog Polym Sci 2015; 41: 67-121.

http://dx.doi.org./10.1016/j.progpolymsci.2014.08.001

[26] Ponyrko S, Kobera L, Brus J, Matějka L. Epoxy-silica hybrids by nonaqueous sol-gel process. Polymer 2013; 54: 6271-82. http://dx.doi.org./10.1016/j.polymer.2013.09.034

[27] Piscitelli F, Lavorgna M, Buonocore GG, Verdolotti L, Galy J, Mascia L. Plasticizing and reinforcing features of siloxane domains in aminecured epoxy/silica hybrids. Macromol Mater Eng 2013; 298: 896-909. http://dx.doi.org./10.1002/mame.201200222
Metroke TL, Parkhill RL, Knobbe ET. Passivation of metal alloys using sol-gel-derived materials - a review. Prog Org Coat 2001; 41: 233-8. http://dx.doi.org./10.1016/S0300-9440(01)00134-5

[29] Raps D, Hack T, Wehr J, et al. Electrochemical study of inhibitorcontaining organic-inorganic hybrid coatings on AA2024. Corros Sci 2009; 51: 1012-21.

http://dx.doi.org./10.1016/i.corsci.2009.02.018

[30] Yasakau KA, Zheludkevich ML, Karavai OV, Ferreira MGS. Influence of inhibitor addition on the corrosion protection performance of sol-gel coatings on AA2024. Prog Org Coat 2008; 63: 352-61.

http://dx.doi.org./10.1016/j.porgcoat.2007.12.002

[31] Zheng S, Li J. Inorganic-organic sol gel hybrid coatings for corrosion protection of metals. J Sol-Gel Sci Technol 2010; 54: 174-87. http://dx.doi.org./10.1007/s10971-010-2173-1

[32] Palanivel V, Huang $\mathrm{Y}$, van Ooij WJ. Effects of addition of corrosion inhibitors to silane films on the performance of AA2024-T3 in a $0.5 \mathrm{M}$ $\mathrm{NaCl}$ solution. Prog Org Coat 2005; 53: 153-68. http://dx.doi.org./10.1016/i.porgcoat.2003.07.008

[33] Quinet M, Neveu B, Moutarlier V, Audebert P, Ricq L. Corrosion protection of sol-gel coatings doped with an organic corrosion inhibitor: Chloranil. Prog Org Coat 2007; 58: 46-53. http://dx.doi.org./10.1016/j.porgcoat.2006.11.007

[34] Zheludkevich ML, Serra R, Montemor MF, Yasakau KA, Salvado IMM, Ferreira MGS. Nanostructured sol-gel coatings doped with cerium nitrate as pre-treatments for AA2024-T3: corrosion protection performance. Electrochimica Acta 2005; 51: 208-17. http://dx.doi.org./10.1016/i.electacta.2005.04.021

[35] Voevodin NN, Grebasch NT, Soto WS, Arnold FE, Donley MS Potentiodynamic evaluation of sol-gel coatings with inorganic inhibitors. Surf Coat Technol 2001; 140: 24-8. http://dx.doi.org./10.1016/S0257-8972(01)00999-9

[36] Khramov AN, Voevodin NN, Balbyshev VN, Mantz RA. Sol-gelderived corrosion-protective coatings with controllable release of incorporated organic corrosion inhibitors. Thin Solid Films 2005; 483 191-6.

http://dx.doi.org./10.1016/j.tsf.2004.12.021

[37] Zheludkevich ML, Yasakau KA, Poznyak SK, Ferreira MGS. Triazole and thiazole derivatives as corrosion inhibitors for AA2024 aluminium alloy. Corros Sci 2005; 47: 3368-83. http://dx.doi.org./10.1016/j.corsci.2005.05.040

[38] Zandi-Zand R, Ershad-Langroudi A, Rahimi A. Silica based organicinorganic hybrid nanocomposite coatings for corrosion protection. Prog Org Coat 2005; 53: 286-91. http://dx.doi.org./10.1016/j.porgcoat.2005.03.009

[39] Farias MA, Coelho LAF, Pezzin SH. Epoxy/silsesquioxane organicinorganic hybrids: sol-gel synthesis of inorganic precursors containing amino and phenyl groups. Polym Eng Sci 2012; 52: 52-61. http://dx.doi.org./10.1002/pen.22044

[40] Han Y-H, Taylor A, Knowles KM. Characterisation of organicinorganic hybrid coatings deposited on aluminium substrates. Surf Coat Technol 2008; 202: 1859-68. http://dx.doi.org./10.1016/j.surfcoat.2007.08.006

[41] Kumar N, Jyothirmayi A, Soma Raju KRC, Subasri R. Effect of functional groups (methyl, phenyl) on organic-inorganic hybrid sol-ge silica coatings on surface modified SS 316. Ceram Int 2012; 38: 656572.

http://dx.doi.org./10.1016/j.ceramint.2012.05.040

[42] Yasakau KA, Zheludkevich ML, Karavai OV, Ferreira MGS. Influence of inhibitor addition on the corrosion protection performance of sol-gel coatings on AA2024. Prog Org Coat 2008; 63: 352-61. http://dx.doi.org./10.1016/i.porgcoat.2007.12.002

[43] Floyd FL, Avudaiappan S, Gibson J, et al. Using electrochemical impedance spectroscopy to predict the corrosion resistance of unexposed coated metal panels. Prog Org Coat 200; 66: 8-34. http://dx.doi.org./10.1016/j.porgcoat.2009.04.009 